\title{
晚渐新世以来中国黄土高原风成红粘土序列的 发现：亚洲内陆干旱化起源的新记录
}

强小科 ${ }^{(1)}$, 安芷生 ${ }^{(1)}$, 宋友桂 ${ }^{(1)}$, 常宏 ${ }^{(1)}$, 孙有斌 ${ }^{(1)}$, 刘卫国 ${ }^{(1)}$, 敖红 ${ }^{(1)}$, 董吉宝 ${ }^{(1)}$,

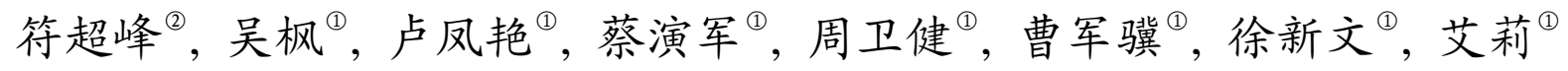

(1) 中国科学院地球环境研究所, 黄土与第四纪地质国家重点实验室, 西安 710075;

(2) 长安大学西部矿产资源与地质工程教育部重点实验室, 西安 710054

* 联系人, E-mail: anzs@ loess.llqg.ac.cn

收稿日期: 2010-10-21; 接受日期: 2010-10-29

国家重点基础研究发展计划项目(编号：2010CB833400, 2004CB720200)、中国科学院知识创新工程重要方向项目(编号: KZCX2-YWQ09-04)、国家自然科学基金(批准号: 41072142, 40921120406, 40772116)和黄土与第四纪地质国家重点实验室资助

摘要亚洲内陆荒漠的扩张影响了环境改善及经济社会发展, 受到人们广泛关注. 亚洲 内陆干旱化成为古气候研究热点, 其起始年代始终是这一研究的焦点问题.中国黄土高原 晚新生代风成黄土和红粘土沉积作为研究亚洲内陆干旱化的理想载体, 蕴含丰富的古气候 信息. 本文对黄土高原西部庄浪钻孔 $654 \mathrm{~m}$ 的岩芯进行了磁性地层学、沉积学和地球化学研 究. 结果表明, 庄浪岩芯记录了 25.6 4.8 Ma 的连续磁极性变化序列, 主要由高分辨率的风 成红粘土序列构成, 最早的风成红粘土出现于 $25 \mathrm{Ma}$, 表明亚洲内陆干旱化至少在晚渐新世 已经出现, 这为研究晚渐新世以来亚洲内陆干旱化过程提供了不可多得的地质记录.

关键词

黄土高原

风成红粘土

磁性地层

晚渐新世

亚洲内陆干旱化
广泛分布在中国黄土高原的风成黄土-红粘土序 列, 以连续性好、沉积速率高、时间跨度长和含有丰 富的古气候信息为世界所瞩目. 20 世纪 60 年代, 刘 东生和张宗祜 ${ }^{[1]}$ 将中国黄土地层划分为早更新世午 城黄土、中更新世离石黄土和晚更新世马兰黄土, 确 认了黄土的风成成因. 20 世纪 70 年代末至 80 年代初, 中国学者根据黄土剖面中黄土和古土壤层交替出现 的特征, 提出了黄土-古土壤序列的概念 ${ }^{[2,3]}$, 并以此 对黄土进行地层命名和划分 ${ }^{[2,4 ~ 7]}$. 1982 年, Heller和 $\mathrm{Liu}^{[8]}$ 建立了 $2.5 \mathrm{Ma}$ 以来中国黄土-古土壤的磁性地层 序列. 随后, 中外学者将黄土-古土壤序列陆相记录 与深海氧同位素记录进行良好对比 ${ }^{[4,6,9 ~ 17]}$, 使中国黄
土研究推向与全球环境变化研究相结合的新阶段. 20 世纪 90 年代初, 安芷生等 ${ }^{[18,19]}$ 提出黄土高原第四纪 黄土-古土壤序列可视为东亚季风变迁的良好记录, 并揭示晚更新世黄土粉尘通量的时间序列反映了末 次间冰期以来亚洲内陆干燥度变化历史 ${ }^{[14]}$. 孙有斌 等 ${ }^{[20]}$ 、Sun和 $\mathrm{An}^{[21]}$ 根据灵台黄土-红粘土序列重建了 粉尘堆积通量所反映的最近 $7 \mathrm{Ma}$ 亚洲内陆干旱化的 历史.

近些年来, 研究者根据多学科的证据, 证明了黄 土序列下伏红粘土的风成成因 ${ }^{[22 ~ 30]}$. 六盘山以东黄 土高原红粘土的底界主要介于 $6 \sim 8 \mathrm{Ma}^{[31 ~ 39]}$, 新近的 研究又将其底界上溯到 $11 \mathrm{Ma}^{[40]}$ (图 1). 六盘山以西

引用格式: Qiang X K, An Z S, Song Y G, et al. New eolian red clay sequence on the western Chinese Loess Plateau linked to onset of Asian desertification about 25 Ma ago. Sci China Earth Sci, 2010, doi: 10.1007/s11430-010-4126-5 


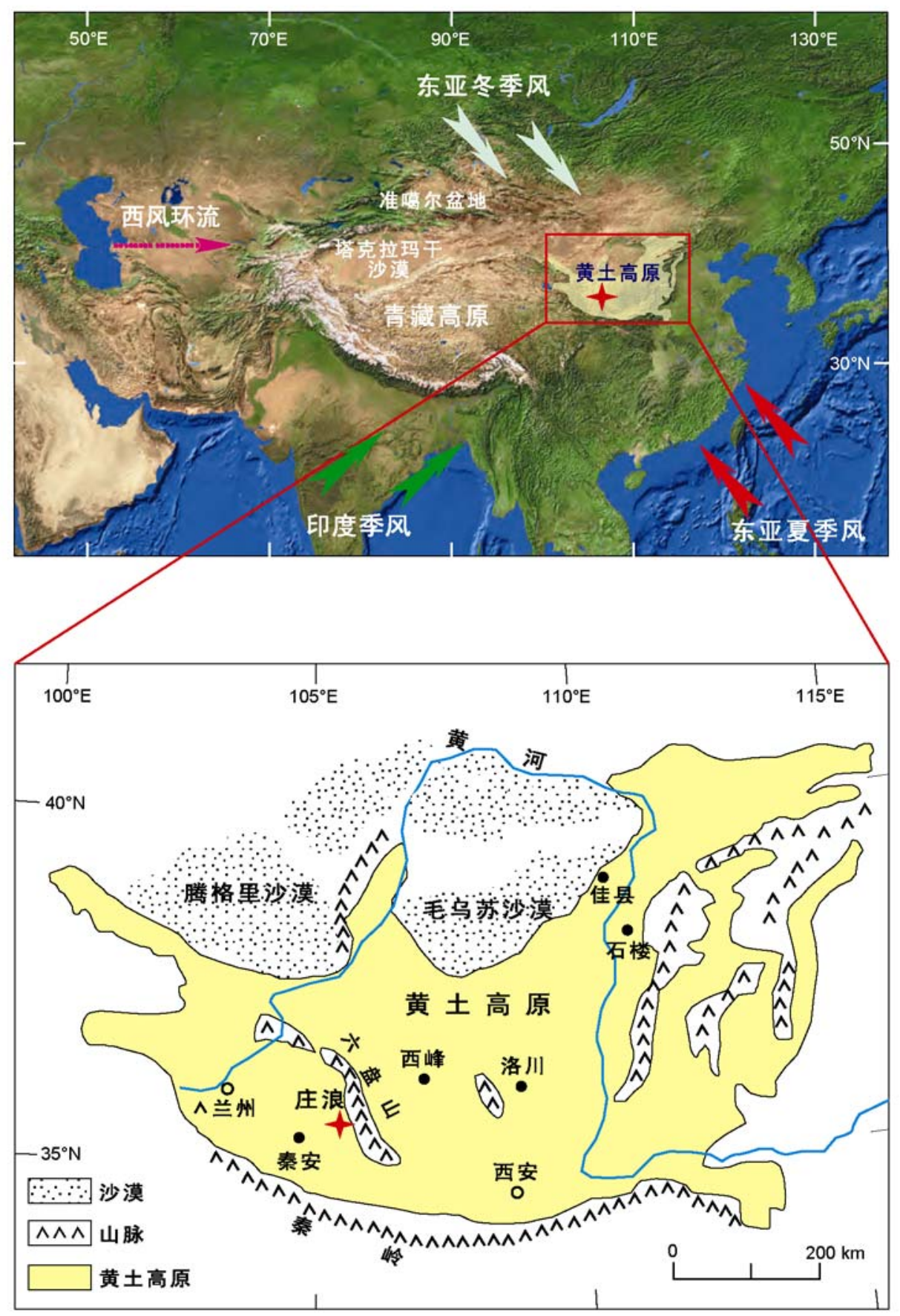

图 1 中国黄土高原、北方沙漠及庄浪钻孔位置以及影响黄土高原气候的大气环流系统

的秦安地区保存有更老的风成红粘土序列(22 6.2 $\mathrm{Ma})^{[41]}$. 秦安红粘土序列的发现表明亚洲内陆荒漠化 在早中新世已经发生. 最近Sun等 ${ }^{[42]}$ 发现新疆准噶尔 盆地存在始于 $24 \mathrm{Ma}$ 的风成红粘土堆积. 然而, 中国 黄土高原是否保存更老的典型风成沉积序列, 它与
内陆干旱化的关系如何，都是尚未解决的问题.

我们通过野外考察和环境钻探发现，六盘山西 侧庄浪一带保存了迄今为止最厚的高分辨率的红粘 土堆积 ${ }^{[43]}$. 本文通过地层岩性、粒度、元素和矿物分 析以及扫描电镜观察等确认了庄浪红粘土堆积的风 
成成因; 根据磁性地层学研究建立了该沉积序列的 年代框架, 将黄土高原西部红粘土的下限从早中新 世延伸到晚渐新世, 为亚洲内陆干旱化起源提供了 新证据.

\section{1 研究区概况与样品采集}

庄浪钻孔 $\left(35^{\circ} 13^{\prime} \mathrm{N}, 106^{\circ} 05^{\prime} \mathrm{E}\right)$ 位于六盘山西侧的 黄土高原, 距西南的秦安剖面 ${ }^{[41]}$ 约 $50 \mathrm{~km}$ (图 1). 区内 丘陵沟壑纵横, 梁状地貌发育. 年平均气温 $8^{\circ} \mathrm{C}$, 年 均降水量 $500 \mathrm{~mm}$, 降雨多集中在 7 9 月. 区内红粘 土出露不完整, 为了获得连续的红粘土沉积记录, 我 们于 2006 年在庄浪进行了两个相距 $1.5 \mathrm{~km}$ 的平行钻 孔取芯. 主孔ZL1 海拔高度 $1993 \mathrm{~m}$, 获取岩芯 555.7 $\mathrm{m}$, 取芯率大于 $97 \%$; 平行孔ZL2 海拔高度 $1643 \mathrm{~m}$, 获取岩芯 $308.5 \mathrm{~m}$, 取芯率约 96\%. 根据岩性、磁性 地层和磁化率等特征, 可将ZL1 和ZL2 孔的岩芯整合 为连续的ZL孔沉积序列, 整合后的沉积厚度为 653.9 m (上部 $450.4 \mathrm{~m}$ 来自ZL1 孔, 下部 $203.5 \mathrm{~m}$ 来自ZL2 孔). 钻孔剖面岩性自下而上为: ( I ) 元古界灰黑色 黑云母片麻岩 $(653.9 \sim 652.3 \mathrm{~m})$. ( II ) 渐新统紫红-桔 红色砂砾石层(652.3 624.8 m). (III) 棕红-棕黄色红 粘土与胶结较好的砂砾石层互层 $(624.8 \sim 584.7 \mathrm{~m})$. 红 粘土具团粒状粉砂质结构, 斑状钙质结核发育, 可见 暗色胶膜. (IV) 棕红-棕黄色红粘土(584.7 $3.34 \mathrm{~m}$ ), 无水平层理; 黄土/弱成壤层与古土壤和钻结核层交 替出现, 前者呈棕黄色, 粉砂质结构, 后者呈深棕红棕红色, 团粒结构明显, 可见暗色胶膜; 钲结核呈斑 状, 散布在古土壤层底部或黄土层上部; 上部 124.32 3.34 m夹薄层棕黄色-棕灰色砂砾石层. ( V) 晚更新世马兰黄土和耕作层(3.34 0 m).

在 ZL1 和 ZL2 孔分别采集了 361 根(约 $529 \mathrm{~m}$ ) 和 162 根(约 $238 \mathrm{~m}$ )U-Channel 条样(专用 U 型无磁古 地磁样槽, $2 \mathrm{~cm} \times 2 \mathrm{~cm} \times 150 \mathrm{~cm}$ ), 并以 $10 \sim 20 \mathrm{~cm}$ 间距 在 ZL1 孔和 ZL2 孔分别采集了 3670 和 1640 块与 U-Channel 样品平行的古地磁定向块样 $(2 \mathrm{~cm} \times 2 \mathrm{~cm} \times 2$ $\mathrm{cm}$ ). 此外, 我们还在一些关键层位(包括钻孔底部 624.8 612.1 $\mathrm{m}$ 的红粘土)采集了块样和粉样.

\section{2 磁性地层}

采用 Bartington MS2 型磁化率仪测量样品的低
频(470 Hz)磁化率. 使用 $2 \mathrm{G} 755$ 型超导磁力仪进行剩 磁测量和交变退磁. U-channel 样品测量天然剩磁后, 在交变磁场下以 5 10 $\mathrm{mT}$ 间隔从 $5 \mathrm{mT}$ 逐步退磁到 80 $\mathrm{mT}$, 测量间距为 $5 \mathrm{~cm}$. 系统热退磁采用 $\mathrm{ASC}$ Scientific TD-48 型热退磁仪, 以 $10 \sim 50^{\circ} \mathrm{C}$ 为间隔逐步 加热到 $690^{\circ} \mathrm{C}$. 样品退磁及剩磁测量在中国科学院地 球环境研究所环境磁学实验室的零磁空间 (<150 nT) 中进行.

庄浪岩芯的天然剩磁强度(NRM)通常在 $10^{-4} \sim$ $10^{-5} \mathrm{~A} / \mathrm{m}$ 量级. 采用正交投影图和主成分分析法对热 退磁和交变退分离出的特征剩磁 (ChRM) 进行分 析 $^{[44,45]}$, 选取至少 4 个连续的剩磁分量投影点进行特 征剩磁方向拟合, 将拟合后最大角偏差(Maximum Angular Deviation, MAD) 小于 $15^{\circ}$ 的特征剩磁方向用 于确定钻孔的磁极性序列. 大多数样品在加热到 $250^{\circ} \mathrm{C}$ 或交变退磁到 $20 \mathrm{mT}$ 后就能消除次生剩磁, 继 续加热至 $585^{\circ} \mathrm{C}$ 或交变退磁到 $80 \mathrm{mT}$ 时就能分离出稳 定的特征剩磁(图 2), 表明磁铁矿是特征剩磁方向的 主要载体. 然而, 部分样品需要加热到 $690^{\circ} \mathrm{C}$ 才能分 离出稳定特征剩磁, 表明具有高矫顽力的赤铁矿的 存在. 对于此类样品, 交变退磁很难分离出稳定的特 征剩磁, 采用热退磁结果. 5310 块热退磁样品中, 有 4880 块( $92 \%)$ 样品获得了可靠的特征剩磁方向. 主要 根据热退磁分离的特征剩磁方向并与交变退磁结果 相比较, 建立了磁极性序列. 结果显示ZL1 孔记录了 39 个正极性带和 39 个负极性带, ZL2 孔记录了 21 个 正极性带和 20 个负极性带(图 3). 整合后的ZL孔共包 含了 44 个正极性带和 43 个负极性带. 将ZL孔的磁极 性序列和岩性柱进一步与标准磁极性序列 ${ }^{[46]}$ 进行对 比(图 4), 获得了从C7An到C3n.3n的磁性地层年代框 架, 年代跨度为 25.6 4.8 Ma. 庄浪钻孔中, 中新世开 始(23.03 Ma)和结束(5.332 Ma)的界限(International Stratigraphic Chart 2009)分别位于 568 和 $29 \mathrm{~m}$. 其中 最早红粘土在 $624.8 \mathrm{~m}$ 出现, 位于C7n.2n亚极性带上 部, 年代约为 $24.85 \mathrm{Ma}$.

ZL孔红粘土的磁化率和磁极性序列均可与邻近 的秦安剖面 ${ }^{[41]}$ 进行良好对比(图 4), 两红粘土序列的 磁化率在变化趋势甚至在细节上均表现出相似变化 特征. 根据磁性地层年代和厚度计算, 庄浪序列沉积 速率为秦安序列的 2 倍以上, 可能是由于庄浪序列位 
(a)

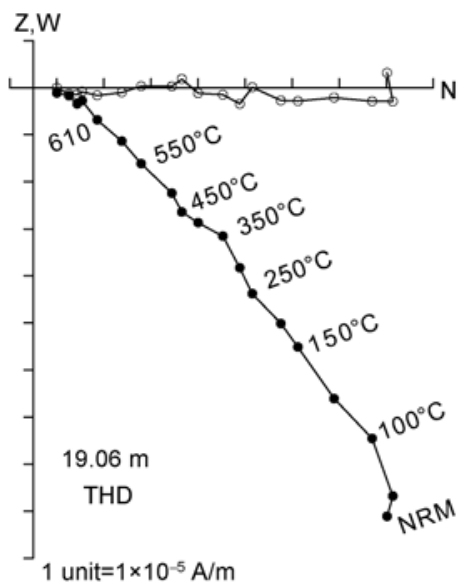

(b)

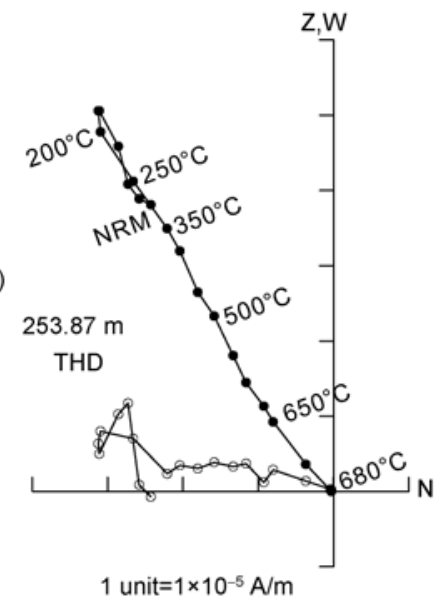

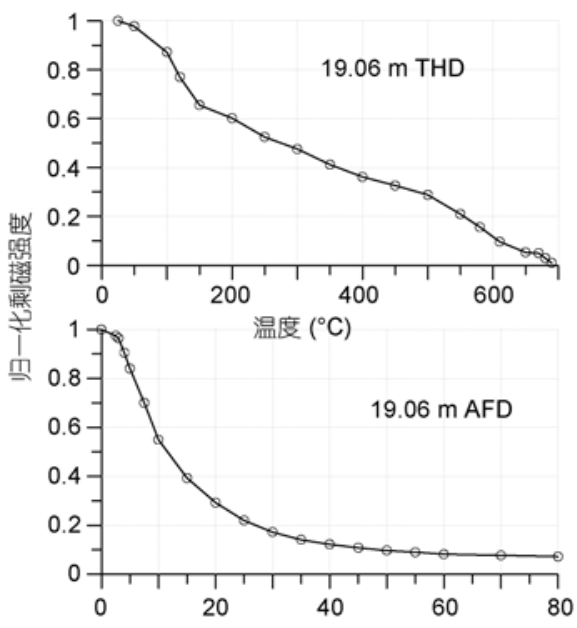

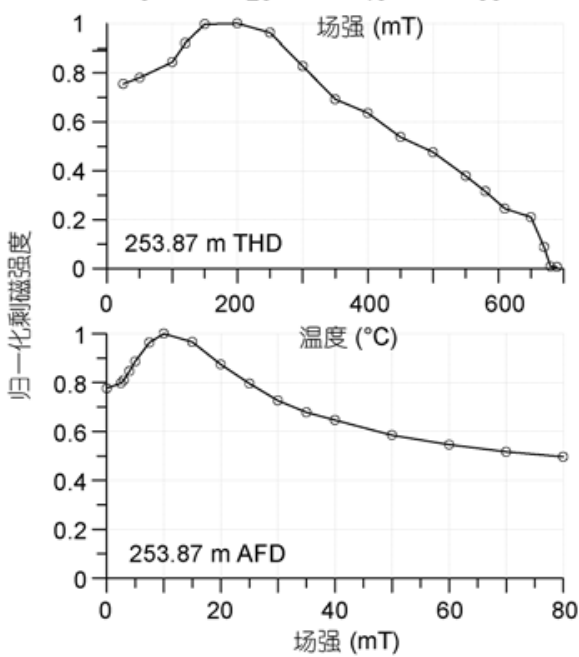

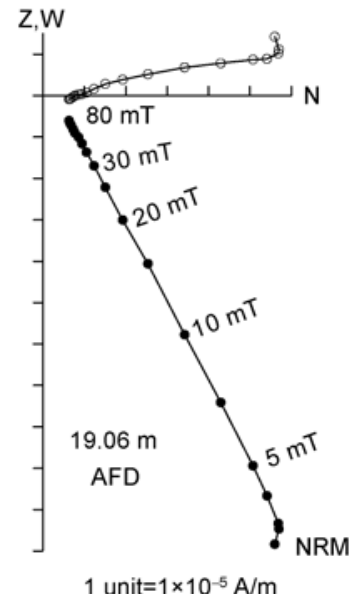

1 unit $=1 \times 10^{-5} \mathrm{~A} / \mathrm{m}$

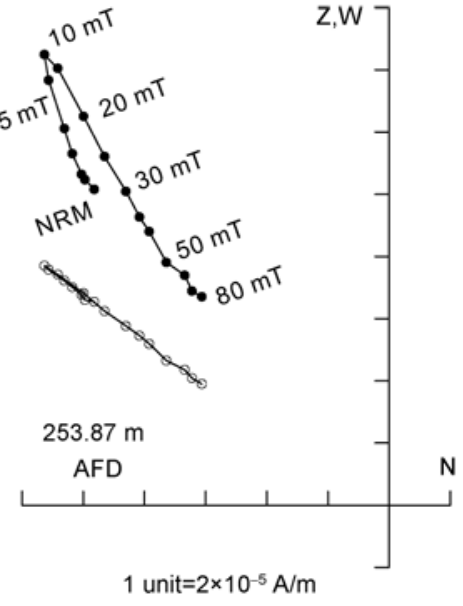

图 2 庄浪红粘土代表样品热退磁(THD)和交变退磁(AFD)过程中剩磁方向的正交矢量投影 ${ }^{[44]}$ 与剩磁衰减图 实心(空心)符号代表垂直(水平)分量投影. (a) $19.06 \mathrm{~m}$ 正极性样品; (b) $253.87 \mathrm{~m}$ 负极性样品

于六盘山西侧翼，处于迎风坡，易于接受更多的粉尘 堆积.

\section{3 风成成因证据}

黄土高原东、西两侧黄土-红粘土堆积具有一致 的风成成因特征 ${ }^{[4,24,25,40,41,47]}$. 类似于秦安剖面, 庄浪 红粘土序列主要由相互交替的黄土和古土壤(包括下 伏的钙结核层)层构成. 为了研究庄浪红粘土序列的 成因, 选取典型层段样品进行粒度、元素、矿物学和 石英颗粒的形态学等分析. 采用Mastersizer 2000 激 光粒度仪进行粒度分析. 将提取的石英颗粒在LEO 1450VP扫描电子显微镜下进行形态观察. 常量元素
和X射线衍射测量分别在PW4400 型X射线苂光光谱 仪和X'Pert Pro MPD型X射线衍射仪上完成. 稀土元 素分析采用感应耦合等离子质谱仪(ICP-MS)在美国 沙漠研究所完成.

图 5 为庄浪岩心 $(\mathrm{ZL})$ 序列典型样品的粒度分布、 常量/稀土元素和矿物组成、石英颗粒微形态特征以 及它们与第四纪黄土-古土壤和上新世红粘土样品的 对比. 庄浪红粘土(包括钻孔底部 624.8 612.1 m 的红 粘土)样品具有与洛川(LC)、西峰(XF) (图 1) 黄土和古 土壤相似的粒度频率分布曲线和累积曲线, 呈似正 态分布. 样品平均粒径为 10 30 $\mu \mathrm{m}$, 粉砂粒级(4 63 $\mu \mathrm{m})$ 含量接近或超过 $80 \%,>63 \mu \mathrm{m}$ 组分含量很少, 具 典型风尘沉积的粒度分布特征(图 5(a)，(b)). 庄浪红 


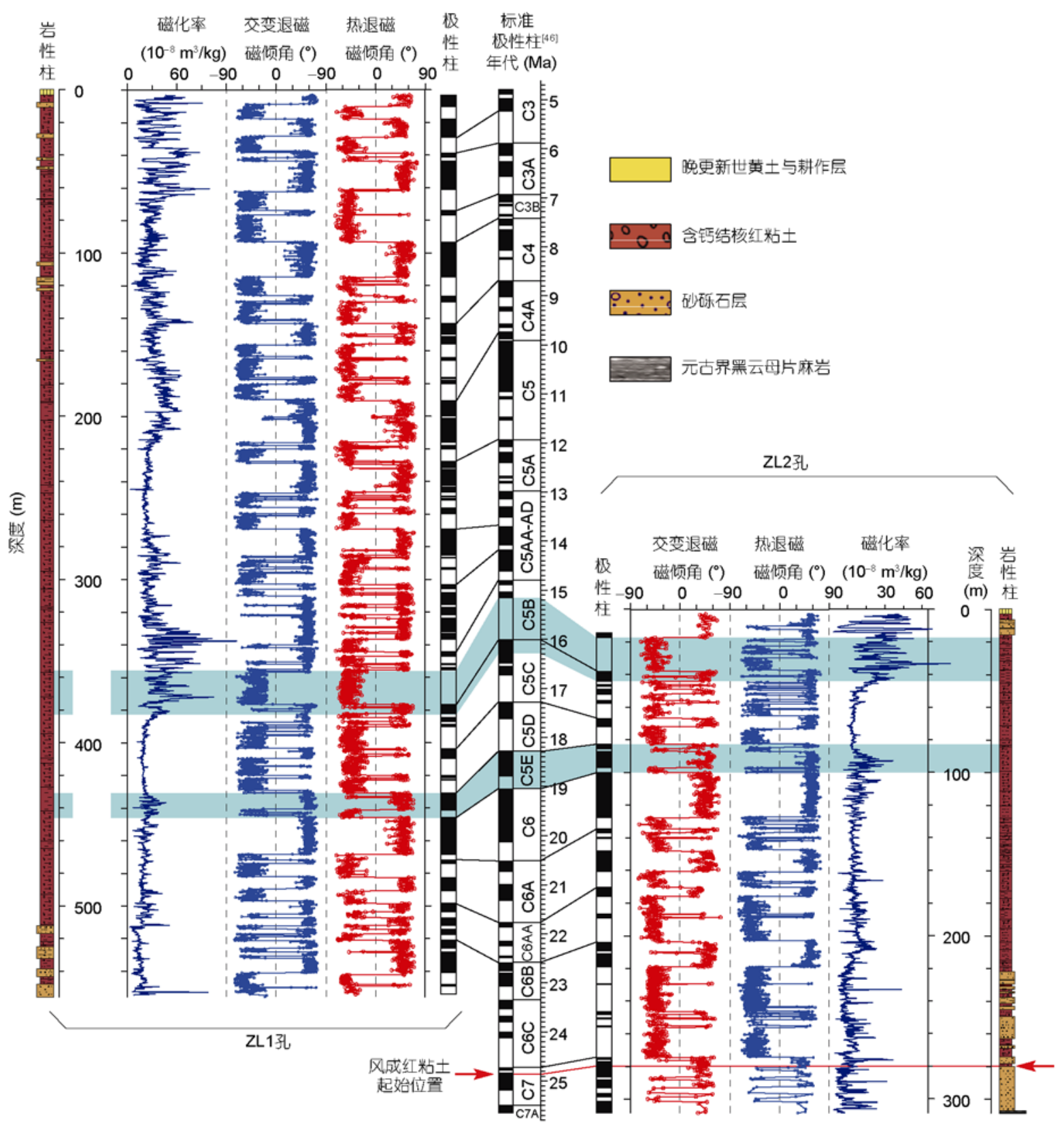

图 3 ZL1 孔和ZL2 孔的岩性柱、磁化率曲线和磁极性序列以及它们与标准极性柱 ${ }^{[46]}$ 的对比

粘土的常量元素组成特征与黄土和古土壤一致(图 5(c)). 矿物组成与黄土和红粘土类似, 以石英为主, 其次为方解石和长石, 含有少量云母和绿泥石(图 5(d)). 稀土元素的配分模式与西峰黄土相似, 表现为 轻稀土富集、重稀土亏损和明显的 $\mathrm{Eu}$ 异常(图 5(e)). 扫描电镜观察显示庄浪红粘土底部样品中的石英颗 粒多呈棱角状和次棱角状, 并见碟状坑等风成沉积 物的典型特征(图 5(f)).

\section{4 讨论与结论}

亚洲内陆干旱区的粉尘物质经风力搬运至黄土 高原堆积形成了连续的黄土-红粘土序列 ${ }^{[4,13,48 \sim 50]}$. 庄 浪红粘土的粒度分布、元素/矿物组成和石英微形态 特征等及其与六盘山以东黄土和红粘土的对比(图 5), 揭示了庄浪红粘土的风成成因, 并表明它们具有相 似或可比较的亚洲内陆粉尘源区和风力搬运模式. 


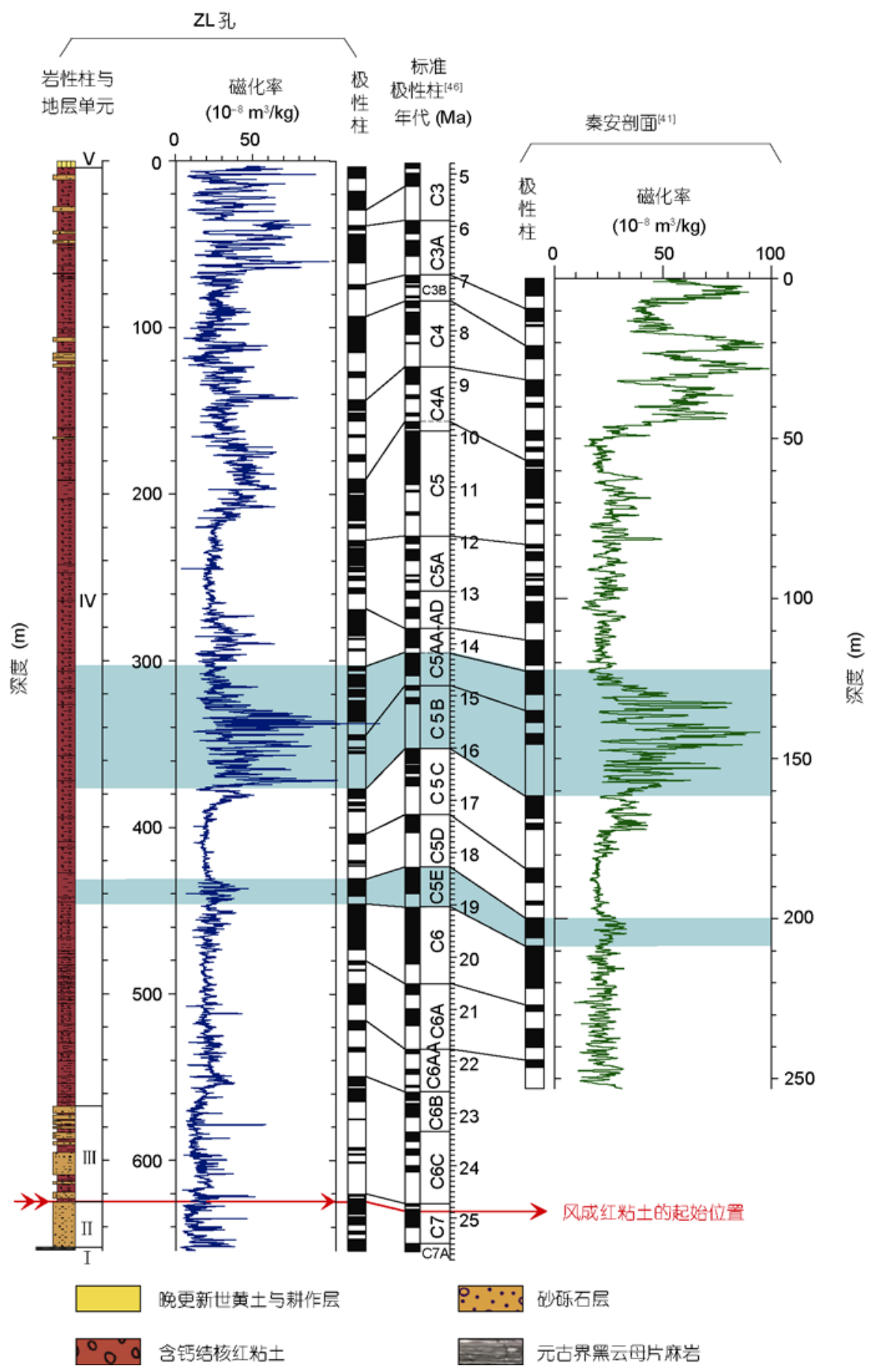

图 4 整合的ZL孔岩芯的磁化率和磁极性序列及其与秦安剖面 ${ }^{[11}$ 和标准极性柱 ${ }^{[46]}$ 的对比

庄浪红粘土最早出现于标准磁性柱的C7n.2n正极性 亚时上部, 时代约 $25 \mathrm{Ma}$. 由于红粘土的形成需要干 旱荒漠环境提供物源, $25 \mathrm{Ma}$ 庄浪红粘土的出现表明 亚洲内陆干旱化至少在晚渐新世已经出现. 这与准
噶尔盆地从 $24 \mathrm{Ma}$ 开始出现红粘土沉积 ${ }^{[42]}$ 、北太平洋 风尘通量在 24 22 Ma急剧增加 ${ }^{[51]}$ 、临夏盆地晚渐新 世湖相沉积中出现风尘组分 ${ }^{[52]}$ 等一致. 25 5 Ma庄浪 红粘土序列为研究亚洲内陆干旱化变迁历史提供 

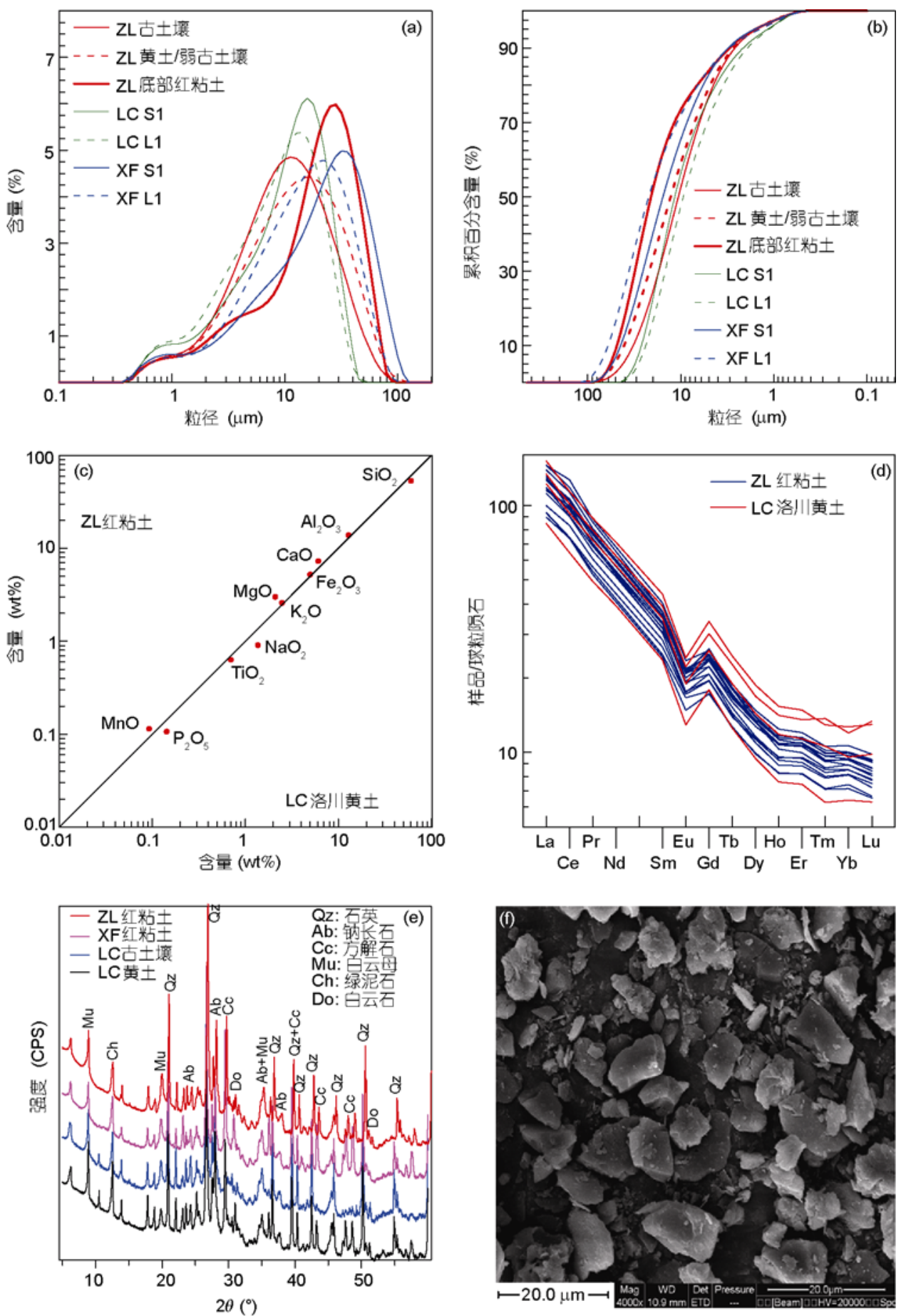

图 5 庄浪红粘土样品的粒度分布、元素矿物组成和石英颗粒微形态及其与第四纪黄土-古土壤和上新世红粘土样品的对比 (a), (b) 庄浪红粘土(ZL)、洛川(LC)和西峰(XF)第四纪黄土和古土壤样品的粒度特征. 频率分布和累积百分含量曲线为多个样品平均的结果. 根据磁化率的变化特征, 选取 ZL 孔(500 30 m) 黄土/弱古土壤和古土壤(各 5 个)、底部(624.8 612.1 m)红粘土(11 个)、洛川 L1 黄土(2 个)和 S1 古土壤 (2 个)、西峰 L1 黄土 (12 个)和 S1 古土壤 (5 个). (c) 庄浪红粘土与洛川第四纪黄土样品常量元素组成的对比. (d) 庄浪红粘土与西峰 第四纪黄土样品稀土元素配分模式的对比. (e) 庄浪红粘土与西峰上新世红粘土、洛川第四纪黄土和古土壤样品矿物组成的对比. (f) 庄浪红 粘土样品石英颗粒的微形态特征 
了不可多得的高分辨率地质记录.

晚中新世以来的黄土和红粘土是主要是由东亚 冬季风环流搬运形成的粉尘堆积 ${ }^{[19,25,36]}$. Guo 等 ${ }^{[41]}$ 认 为中新世秦安红粘土粉尘堆积主要由冬季风搬运而 成, Sun等 ${ }^{[42]}$ 认为新疆准噶尔盆地的红粘土堆积受控 于西风环流. 考虑到位于海拔高达约 $2000 \mathrm{~m}$ 的庄浪 地区冬半年既受冬季风也受西风气流的影响, 庄浪 红粘土堆积可能受东亚冬季风和西风环流的共同影 响.

致谢
亚洲内陆荒漠化是新生代北半球气候变化的重 要特征 ${ }^{[53 ~ 55]}$. 青藏高原隆升是导致亚洲内陆干旱化 的重要动力 ${ }^{[41,55,56]}$. 晚渐新世青藏高原南部的构造隆 升 ${ }^{[57]}$ 阻档了来自南方大洋的水汽，导致了亚洲内陆 干旱化的增强 ${ }^{[55,56]}$. 数值模拟表明青藏高原从无山 到全山的隆升和生长导致亚洲内陆降水和水汽的显 著减少 ${ }^{[55,58]}$. 晚渐新世亚洲内陆古特提斯海的萎缩, 也是内陆干旱化的重要原因 ${ }^{[59]}$.

探工作由青海省核工业地质局负责完成; 与朱日祥教授和Peter Molnar 教授进行了有益的讨论; 中国科学 院地球环境研究所、黄土与第四纪地质国家重点实验室朱崇抒、曾承、王宁和侯昭华等参加了部分野外钻探 与实验室工作, 在此一并致谢.

\section{参考文献}

1 刘东生, 张宗祜. 中国的黄土. 地质学报, 1962, 42: 1-14

2 卢演俦, 安芷生. 约 70 万年以来黄土高原自然环境变化系列探讨. 科学通报, 1979, 24: 221-224

3 刘东生, 文启忠, 郑洪汉, 等. 中国黄土的古气候记录及其反映的古气候演化. 国际交流地质学术论文集(5): 水文地质 工程地质 第四纪地质 地貌. 北京: 地质出版社, 1980. 77-82

4 刘东生, 等. 黄土与环境. 北京: 科学出版社, 1985. 1-481

5 Kukla G, An Z S. Loess stratigraphy in central China. Paleogeogr Paleoclimatol Paleoecol, 1989, 72: 203-233

6 Kukla G, An Z S, Melice J L, et al. Magnetic susceptibility record of Chinese Loess. Trans Royal Soc Edinb-Earth Sci, 1990, 81: 263-288

7 丁仲礼, 刘东生. 中国黄土研究新进展(一) 黄土地层. 第四纪研究, 1989, 1: 24-25

8 Heller F, Liu T S. Magnetostratigraphical dating of loess deposits in China. Nature, 1982, 300: 431-433

9 安芷生, 卢演俦. 华北晚更新世马兰期气候地层划分. 科学通报, 1984, 29: 228-231

10 Sadao S, Wang Y Y. Magneto and chronostratigraphy revealed from the Luochuan loess sequence in China and its relevance to the Quaternary climatic change. In: Sadao S, Wang Y Y, eds. The Recent Research of Loess in China. Kyoto: Wako Printing, Ltd, 1984. 211230

11 Kukla G, Heller F, Ming L X. Pleistocene climates in China dated by magnetic susceptibility. Geology, 1988, 16: 811—814

12 丁仲礼, 刘东生. 1.8 Ma 以来黄土-深海古气候记录对比. 科学通报, 1991, 18: 1401-1403

13 An Z S, Kukla G J, Porter S C, et al. Magnetic susceptibility evidence of monsoon variation on the Loess Plateau of central China during the last 130,000 years. Quat Res, 1991, 36: 29-36

14 An Z S, Kukla G J, Porter S C, et al. Late Quaternary dust flow on the Chinese Loess Plateau. Catena, 1991, 18: 125-132

15 Rutter N, Ding Z L, Evans M E, et al. Baoji-type pedostratigraphic section, Loess Plateau, north-central China. Quat Sci Rev, 1991, 10: 122

16 Rutter N W, Ding Z L, Evans M E, et al. Paleoclimates and monsoon variations interpreted from micromorphogenic features of Baoji paleosols, China. Quat Sci Rev, 1993, 12: 853-862

17 Ding Z L, Yu Z W, Rutter N W, et al. Towards an orbital time scale for Chinese loess deposits. Quat Sci Rev, 1994, 13: 39-70

18 An Z S, Liu T S, Lu H Y, et al. The long-term paleomonsoon variation recorded by the loess-paleosol sequence in central China. Quat Int, 1990, 718: 91-95

19 安芷生, 吴锡浩, 汪品先, 等. 最近 $130 \mathrm{ka}$ 中国古季风—-II 古季风变迁. 中国科学 B 辑, 1991, 11: 1209-1215

20 孙有斌, 鹿化瑨, 安芷生. 黄土-古土壤中石英颗粒的粒度分布. 科学通报, 2000, 45: 2094-2097

21 Sun Y B, An Z S. Late Pliocene-Pleistocene changes in mass accumulation rates of eolian deposits on the central Chinese Loess Plateau. J Geophys Res, 2005, 110: D23101, doi: 10.1029/ 2005JD006064

22 Liu T S. Loess in China. 2nd ed. Beijing: China Ocean Press; Berlin, Heidelberg: Springer-Verlag, 1988. 1-224

23 赵景波. 西安、山西保德第三纪晚期红土研究. 沉积学报, 1989, 7: 113-120 
24 丁仲礼, 孙继敏, 朱日祥, 等. 黄土高原红粘土成因及上新世北方干旱化问题. 第四纪研究, 1997, 2: 147一157

25 Ding Z L, Sun J M, Liu T S, et al. Wind-blown origin of the Pliocene red clay formation in the central Loess Plateau, China. Earth Planet Sci Lett, 1998, 161: 135-143

26 Lu H Y, Vandenberghe J, An Z S. Aeolian origin and paleoclimatic implications of the 'Red Clay' (North China) as evidenced by grain-size distribution. J Quat Sci, 2001, 16: 89-97

27 Yang S L, Ding Z L. Comparison of particle size characteristics of the Tertiary 'red clay' and Pleistocene loess in the Chinese Loess Plateau: Implications for origin and sources of the 'red clay'. Sedimentology, 2004, 51: 77-93

28 刘进峰, 郭正堂, 郝青正, 等. 秦安中新世黄土-古土壤序列石英颗粒形态特征、粒度分布及其对成因的指示意义. 科学通报, 2005 , 50: $2806-2809$

29 乔彦松, 郭正堂, 郝青正, 等. 中新世黄土-古土壤序列的粒度特征及其对成因的指示意义. 中国科学 D 辑: 地球科学, 2006,36 : 646 $-653$

30 Li F J, Wu N Q, Pei Y P, et al. Wind-blow origin of Dongwan late Miocene-Pleiocene dust sequence documented by land snail record in western Chinese Loess Plateau. Geology, 2006, 34: 405-408

31 孙东怀, 刘东生, 陈明扬, 等. 中国黄土高原红粘土序列的磁性地层与气候变化. 中国科学 D 辑: 地球科学, 1997, 27: 265一 270

32 Sun D H, Shaw J, An Z S, et al. Magnetostratigraphy and paleoclimatic interpretation of a continuous 7.2 Ma Late Cenozoic eolian sediments from the Chinese Loess Plateau. Geophys Res Lett, 1998, 25: 85-88

33 Sun D H, An Z S, Shaw J, et al. Magnetostratigraphy and paleoclimatic significance of late Tertiary aeolian sequences in the Chinese Loess Plateau. Geophys J Int, 1998, 134: 207-212

34 安芷生, 王苏民, 吴锡浩, 等. 中国黄土高原的风积证据: 晚新生代北半球大冰期开始及青藏高原的隆升驱动. 中国科学 $\mathrm{D}$ 辑: 地球 科学, 1998, 28: 481-490

35 丁仲礼, 孙继敏, 杨石岭, 等. 灵台黄土-红粘土序列的磁性地层及其粒度记录. 第四纪研究, 1998, 1: 86一 94

36 Ding Z L, Sun J M, Yang S L, et al. Preliminary magnetostratigraphy of a thick eolian red caly-loess sequence at Lingtai, the Chinese Loess Plateau. Geophys Res Lett, 1998, 25: 1225-1228

37 Ding Z L, Xiong S F, Sun J M, et al. Pedostratigraphy and paleomagnetism of a similar to 7.0 Ma eolian loess-red clay sequence at Lingtai, Loess Plateau, north-central China and the implications for paleomonsoon evolution. Palaeogeogr Palaeoclimatol Palaeoecol, 1999, 152: 49 $-66$

38 宋友桂, 方小敏, 李吉均, 等. 六盘山东麓朝那剖面红粘土年代及其意义. 第四纪研究, 2000, 20: 2182一 2185

39 Qiang X K, Li Z X, Powell C McA, et al. Magnetostratigraphic record of the Late Miocene onset of the East Asian monsoon, and Pliocene uplift of northern Tibet. Earth Planet Sci Lett, 2001, 187: 83-93

40 Xu Y, Yue L P, Li J X, et al. An 11-Ma-old red clay sequence on the Eastern Chinese Loess Plateau. Paleogeogr Paleoclimatol Paleoecol, 2009, 284: 383-391

41 Guo Z T, Ruddiman W F, Hao Q Z, et al. Onset of Asian desertification by 22 Myr ago inferred from loess deposits in China. Nature, 2002, 416: $159-163$

42 Sun J M, Ye J, Wu W Y, et al. Late Oligocene-Miocene mid-latitude aridification and wind patterns in the Asian interior. Geology, 2010, 38: $515-518$

43 Qiang X K, An Z S, Fu C F, et al. Magnetostratigraphy of Zhuanglang drilling core from western Loess Plateau. The 5th International Symposium on Tibetan Plateau \& the 24th Himalaya-Karakorum-Tibet Workshop. 11-14 August 2009, Beijing, China, 2009. S2.7, 69

44 Zijderveld J D A. AC demagnetization of rocks: Analysis of results. In: Collinson D W, Runcorn S K, Creer K M, eds. Methods in Paleomagnetism. New York: Elsevier, 1967. 254-286

45 Kirschvink J L. The least-squares line and plane and the analysis of paleomagnetic data. Geophys J Royal Astron Soc, 1980,62 : 699-718

46 Cande S C, Kent D V. Revised calibration of the geomagnetic polarity timescale for the late Cretaceous and Cenozoic. J Geophys Res, 1995, 100: $6093-6095$

47 刘进峰, 郭正堂, 乔彦松, 等. 秦安中新世黄土-古土壤序列石英颗粒形态特征、粒度分布及其对成因的指示意义. 科学通报, 2005 , 50: $2806-2809$

48 Ding Z L, Rutter N W, Sun J M, et al. Re-arrangement of atmospheric circulation at about 2.6 Ma over northern China: Evidence from grain size records of loess-palaeosol and red clay sequences. Quat Sci Rev, 2000, 19: 547-558

49 Sun J M. Provenance of loess material and formation of loess deposits on the Chinese Loess Plateau. Earth Planet Sci Lett, 2002, 203: 845 $-859$

50 Guo Z T, Sun B, Zhang Z S, et al. A major reorganization of Asian climate by the early Miocene. Clim Past, 2008, 4: 153-174 
51 Rea D K, Leinen M, Janecek T R. Geologic approach to the long-term history of atmospheric circulation. Science, 1985, 227: 721-725

52 Garzione C N, Ikari M J, Basu A R. Source of Oligocene to Pliocene sedimentary rocks in the Linxia Basin in northeastern Tibet from Nd isotopes: Implications for tectonic forcing of climate. Geol Soc Am Bull, 2006, 117: 1156-1166

53 Ruddimman W F, Kutzbach J K. Forcing of late Cenozoic northern hemisphere climate by plateau uplift in southern Asia and American West. J Geophys Res, 1989, 94: 18409-18427

54 Manabe S, Broccoli A J. Mountains and arid climates of middle latitudes. Science, 1990, 247: 192-195

55 An Z S, Kutzbach J E, Prell W L, et al. Evolution of Asian monsoons and phased uplift of the Himalayan Tibetan Plateau since Late Miocene times. Nature, 2001, 411: 62-66

56 Kutzbach J E, Guetter P J, Ruddimman W F, et al. Senseitivity of climate to Late Cenozoic uplift in southern Asia and the American West: Numerical experiments. J Geophys Res, 1989, 94: 18393-18407

57 Harrison T M, Copeland P, Kidd W S F, et al. Raising Tibet. Science, 1992, 255: 1663-1670

58 Kutzbach J E, Prell W L, Ruddimman W F. Sensitivity of Eurasian climate to surface uplift of the Tibetan Plateau. J Geol, 1993, 101: 177190

59 Ramstein G, Fluteau F, Besse J, et al. Effect of orogeny, plate motion and land-sea distribution on Eurasian climate change over the past 30 million years. Nature, 1997, 386: 788-795 